Pacific Journal of Mathematics

DIAGONAL SIMILARITY OF IRREDUCIBLE MATRICES TO 


\title{
DIAGONAL SIMILARITY OF IRREDUCIBLE MATRICES TO ROW STOCHASTIC MATRICES
}

\author{
D. J. Hartfiel and J. W. Spellmann
}

By using the Perron-Frobenius Theorem it is easily shown that if $A$ is an irreducible matrix then there is a diagonal matrix $D$ with positive main diagonal so that $D A D^{-1}=r S$ where $r$ is a positive scalar and $S$ a stochastic matrix. This paper gives a short proof of this result without direct appeal to the Perron-Frobenius Theorem.

Definitions and Notations. Let $n \geqq 2$ be an integer. Let $N=$ $\{1,2, \cdots, n\}$. An $n \times n$ nonnegative matrix $A$ is said to be reducible if there is a permutation matrix $P$ so that

$P A P^{T}=\left(\begin{array}{ll}A_{1} & 0 \\ B & A_{2}\end{array}\right)$ where $A_{1}$ and $A_{2}$ are square. If $A$ is not reducible we say that $A$ is irreducible. By agreement each $1 \times 1$ matrix is irreducible.

Denote by

$$
u(A)=\min _{M}\left[\max _{\substack{i \in M \\ j \notin M}} a_{i j}\right]
$$

where the minimum is over all proper subsets of $N$.

$$
\begin{aligned}
r(A) & =\max _{i \in N} \sum_{k \in N} a_{i k}, \quad p(A)=\min _{i \in N} \sum_{k \in N} a_{i k} \\
D & =\left\{d=\left(d_{1}, d_{2}, \cdots, d_{n}\right) \mid \text { each } d_{k}>0 \text { and } \min _{k} d_{k}=1\right\} .
\end{aligned}
$$

$f(d)=\max _{i j \in N}\left|\sum_{k \in N} d_{i} a_{i k} d_{k}^{-1}-\sum_{k \in N} d_{j} a_{j_{k}} d_{k}^{-1}\right|$ where each $d_{k}>0$ and $A$ is irreducible. Finally let $S(A)$ denote the positive number so that $S(A) \cdot u(A)-r(A)=f(e)$ where $e=(1,1, \cdots, 1)$.

\section{RESUlts.}

Lemm $+1: \quad f(d)=f(\lambda \cdot d)$ for each $\lambda>0$.

Lemma 2. If $\left(d_{1}, d_{2}, \cdots, d_{n}\right) \in D$, and $\max _{k \in N} d_{k}>[S(A)]^{n-1}$, then $f(d)>f(e)$.

Proof. Reorder $\left(d_{1}, d_{2}, \cdots, d_{n}\right)$ to $\left(d_{i_{1}}, d_{i_{2}}, \cdots, d_{i_{n}}\right)$ so that $d_{i_{1}} \geqq$ $d_{i_{2}} \geqq \cdots \geqq d_{i_{n}}$. Let $s$ denote the smallest integer so that $\left(d_{i_{s}} / d_{i_{s+1}}\right)>$ $S(A)$. That there is such an $s$ follows since $\left(d_{i_{k}} / d_{i_{k+1}}\right) \leqq S(A)$ for each $k \in\{1,2, \cdots, n-1\}$ would imply that 


$$
d_{i_{1}}=\frac{d_{i_{1}}}{d_{i_{n}}}=\prod_{k=1}^{n-1}\left(\frac{d_{i_{k}}}{d_{i_{k+1}}}\right) \leqq[S(A)]^{n-1}
$$

Let $M=\left\{d_{i_{1}}, d_{i_{2}}, \cdots, d_{i_{s}}\right\}$. Note that $M \neq N$. Since $A$ is irreducible there is an $a_{p q}=\max _{i \in M, j \notin M} a_{i j}>0$. Then since $p \in M$ and $q \notin M$

$$
\begin{gathered}
\frac{d_{p}}{d_{q}}>S(A), \frac{d_{i_{n}}}{d_{k}} \leqq 1 \text { for each } k \in N, \\
\sum_{k \in N} d_{p} a_{p k} d_{k}^{-1}>S(A) \cdot u(A), \text { and } \sum_{k \in N} d_{i_{n}} a_{i_{n} k} d_{k}^{-1} \leqq r(A) .
\end{gathered}
$$

From this it follows that

$$
f(d) \geqq\left|\sum_{k \in N} d_{p} a_{p k} d_{k}^{-1}-\sum_{k \in N} d_{i_{n}} a_{i_{n} k} d_{k}^{-1}\right|>S(A) \cdot u(A)-r(A)=f(e) .
$$

Lemm4 3. $f$ achieves a minimum in $D$.

Proof. The proof follows from Lemma 2, the fact that $f$ is continuous on the compact set $\left\{d \mid d \in D\right.$ and $\left.\max _{k} d_{k} \leqq[S(A)]^{n-1}\right\}$, and $e \in D$.

Theorem. The minimum of $f$ in $D$ is 0 , i.e., $\operatorname{Min}_{d_{k}>0<\in N} f(d)=0$.

Proof. We first prove the theorem for positive matrices. Suppose $A>0$ and $f$ achieves its minimum at $d^{0}=\left(d_{1}^{0}, d_{2}^{0}, \cdots, d_{n}^{0}\right) \in D$. Further suppose $f\left(d^{0}\right)>0$. Let $D_{0}=$ diagonal $\left(d_{1}^{0}, d_{2}^{0}, \cdots, d_{n}^{0}\right)$. Let $D_{0} A D_{0}^{-1}=B$. If $P$ is a permutation matrix then $\left(P D_{0} P^{T}\right) P A P^{T}\left(P D_{0}^{-1} P^{T}\right)=P B P^{T}$. Hence we may assume that

$$
\sum_{k \in, Y} b_{1 k} \geqq \sum_{k \in, N} b_{2 k} \geqq \cdots \geqq \sum_{k \in, V} b_{n k} .
$$

Let

$$
M_{1}=\left\{i \mid \sum_{k \in N} b_{i k}=\sum_{k \in N} b_{1 k}\right\} \quad M_{2}=\left\{i \mid \sum_{k \in V} b_{i k}=\sum_{k \in N} b_{n k}\right\} .
$$

Let

$$
d_{k}= \begin{cases}1-\varepsilon & k \in M_{1} \\ (1-\varepsilon)^{-1} & k \in M_{2} \\ 1 & \text { otherwise }\end{cases}
$$

Consider $D B D^{-1}$ and let $g(\varepsilon)$

Then

$$
=\sum_{k \in \mathcal{V}} d_{i} b_{i k} d_{k}^{-1}-\sum_{k \in N} d_{j} b_{j k} d_{k}^{-1} \quad i \in M_{1}, j \in M_{2} \text {. }
$$

$$
g^{\prime}(0)=-\sum_{\substack{k \notin M_{1} \\ k \notin M_{2}}} b_{i k}-2 \sum_{k \in M_{2}} b_{i k}-2 \sum_{k \in M_{1}} b_{j k}-\sum_{\substack{k \notin M_{1} \\ k \notin M_{2}}} b_{j k}<0 .
$$


Hence for sufficiently small $\varepsilon$,

$$
f_{A}\left[d_{1} d_{1}^{0}, d_{2} d_{2}^{0}, \cdots, d_{n} d_{n}^{0}\right]<f\left(d^{0}\right) .
$$

However, this contradicts $f$ having its minimum at $d^{0}$. Therefore, if $A>0, \min _{d_{k}>0, k \in \lambda} f(d)=0$.

Now suppose $A$ is irreducible. For each positive integer $k$, let $A_{k}=A+(1 / k) J$ where $J$ is the $n \times n$ matrix of ones so that $\lim _{m \rightarrow \infty} A_{m}=$ $A$. For each $A_{m}$ there is a diagonal matrix $D_{m}=\operatorname{diag} .\left(d_{1}^{m}, d_{2}^{m}, \cdots, d_{n}^{m}\right)$, $\left(d_{1}^{m}, d_{2}^{m}, \cdots, d_{n}^{m}\right) \in D$, so that $D_{m} A_{m} D_{m}^{-1}$ has equal row sums. Further

$$
1 \leqq d_{k}^{m} \leqq\left[S\left(A_{m}\right)\right]^{n-1} \text { for each } k \in N \text {. }
$$

The $S\left(A_{m}\right)$ 's are easily seen to be bounded, and hence the $D_{m}$ 's are bounded having a limit point $D$. Let $\left\{D_{m^{\prime}}\right\}$ denote a subsequence of $\left\{D_{m}\right\}$ so that $\lim _{m \rightarrow \infty} D_{m^{\prime}}=D$. Then $\lim _{m \rightarrow \infty} D_{m^{\prime}} A_{m^{\prime}} D_{m^{\prime}}^{-1}=D A D^{-1}$ which has all its row sums equal. Hence $\min _{d_{k}>0 k \in \mathrm{N}} f(d)=0$.

COROLlary. If $A$ is an irreducible matrix then there is a diagonal matrix $D$ with positive main diagonal so that $D A D^{-1}=r S$ where $S$ is a row stochastic matrix and $r$ a positive number.

We also include the following corollary to Lemma 2.

Corollary. If $A$ is irreducible with Perron eigenvector $a=$ $\left(x_{1}, x_{2}, \cdots, x_{n}\right)$ then $\max _{i j} x_{i} / x_{j} \leqq[S(A)]^{n-1}=\left((2 r(A)-p(A) / u(A))^{n-1}\right.$.

We include this bound as the bound involves the quantity $u(A)$ which to our knowledge is new.

\section{REFERENCE}

1. F. R. Gantmacher, The Theory of Matrices. Chelsea Publishing Co. New York, N. Y. (1969).

Received December 4, 1970 and in revised form May 6, 1971.

TEXAS A \& M UNIVERSITY 



\section{PACIFIC JOURNAL OF MATHEMATICS}

\section{EDITORS}

H. SAMELSON

Stanford University

Stanford, California 94305

C. R. HOBBY

University of Washington

Seattle, Washington 98105
J. DugundJI

Department of Mathematics

University of Southern California

Los Angeles, California 90007

RICHARD ARENS

University of California

Los Angeles, California 90024

\section{ASSOCIATE EDITORS}

E. F. BeCKENBACH

B. H. NeumanN

F. WOLF

K. YosHIDA

\section{SUPPORTING INSTITUTIONS}

UNIVERSITY OF BRITISH COLUMBIA

CALIFORNIA INSTITUTE OF TECHNOLOGY

UNIVERSITY OF CALIFORNIA

MONTANA STATE UNIVERSITY

UNIVERSITY OF NEVADA

NEW MEXICO STATE UNIVERSITY

OREGON STATE UNIVERSITY

UNIVERSITY OF OREGON

OSARA UNIVERSITY
UNIVERSITY OF SOUTHERN CALIFORNIA STANFORD UNIVERSITY

UNIVERSITY OF TOKYO

UNIVERSITY OF UTAH

WASHINGTON STATE UNIVERSITY

UNIVERSITY OF WASHINGTON

AMERICAN MATHEMATICAL SOCIETY

NAVAL WEAPONS CENTER

Printed in Japan by International Academic Printing Co., Ltd., Tokyo, Japan 


\section{Pacific Journal of Mathematics}

\section{Vol. 40, No. $1 \quad$ September, 1972}

Alex Bacopoulos and Athanassios G. Kartsatos, On polynomials

approximating the solutions of nonlinear differential equations........

Monte Boisen and Max Dean Larsen, Prüfer and valuation rings with zero

divisors ..........................................

James J. Bowe, Neat homomorphisms

David W. Boyd and Hershy Kisilevsky, The Diophantine equation

$$
u(u+1)(u+2)(u+3)=v(v+1)(v+2) \ldots \ldots \ldots \ldots \ldots \ldots \ldots
$$

George Ulrich Brauer, Summability and Fourier analysis ...............

Robin B. S. Brooks, On removing coincidences of two maps when only one,

rather than both, of them may be deformed by a homotopy ............

Frank Castagna and Geert Caleb Ernst Prins, Every generalized Petersen

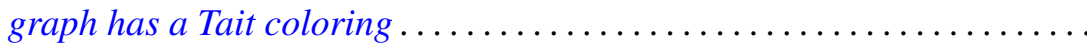

Micheal Neal Dyer, Rational homology and Whitehead products ..........

John Fuelberth and Mark Lawrence Teply, The singular submodule of a

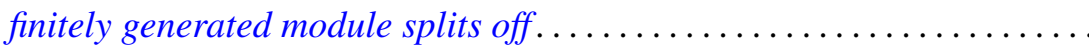

Robert Gold, $\Gamma$-extensions of imaginary quadratic fields ............ 83

Myron Goldberg and John W. Moon, Cycles in k-strong tournaments.......

Darald Joe Hartfiel and J. W. Spellmann, Diagonal similarity of irreducible

matrices to row stochastic matrices...............

Wayland M. Hubbart, Some results on blocks over local fields ..

Alan Loeb Kostinsky, Projective lattices and bounded homomorphisms....

Kenneth O. Leland, Maximum modulus theorems for algebras of operator

valued functions ...

Jerome Irving Malitz and William Nelson Reinhardt, Maximal models in the

language with quantifier "there exist uncountably many" ..

John Douglas Moore, Isometric immersions of space forms in space

forms.

Ronald C. Mullin and Ralph Gordon Stanton, A map-theoretic approach to

Davenport-Schinzel sequences ....................

Chull Park, On Fredholm transformations in Yeh-Wiener space. .

Stanley Poreda, Complex Chebyshev alterations ..............

Ray C. Shiflett, Extreme Markov operators and the orbits of Ryff. ...

Robert L. Snider, Lattices of radicals .....................

Ralph Richard Summerhill, Unknotting cones in the topological

category ................................

Charles Irvin Vinsonhaler, A note on two generalizations of $\mathrm{QF}-3 \ldots \ldots 229$

William Patterson Wardlaw, Defining relations for certain integrally

parameterized Chevalley groups...................

William Jennings Wickless, Abelian groups which admit only nilpotent

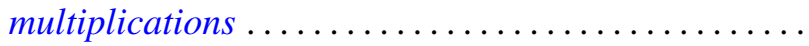

